\title{
Design of Portable Automotive Restraint for Deep Vein Thrombosis
}

\author{
Heena Patel, Brijesh Modi, Jay Raval \\ Biomedical Department, \\ UVPCE, Ganpat University, Kherva, \\ Mahesana, -384012, India
}

\begin{abstract}
The main objective of our paper is to design an Automotive Restraint system to solve the Biological problems such as DEEP VEIN THROMBOSIS, LEG CRAMPING while driving for long distance journey. The right foot is constantly feeding signals to the accelerator either depressing it more or letting off the pressure, for split seconds of time. And every so often pivoting the ball of the foot on the heel to press the brake: The heel of the foot constantly rest on the floor, while the rest of the foot is angled up to press against the accelerator pedal and it last up to long hours or depending on driving hours. So the Ankle joint, ball of the feet, heel and toes are always under stress. This leads to pain in both foot and thigh portion: Pain in the heel, Pain in toes/ball of the foot, Pain in just above the ankle, Muscle strain. Minimize the muscle fatigue and stress we are proposing External Counter Pulsation. In this propose method pneumatic cuffs are automatically wrap around person legs and inflation and deflation of cuff about 200 to $250 \mathrm{mmHg}$ keep the muscle active, improve the blood circulation and prevents the said Problems. We are also proposing the use of heat up to $37^{\circ} \mathrm{C}$ in pulsatile form to stop the pain of ankle and thigh. A sheath of bed in which heat is generated as per requirement and it is fully based on Artificial intelligence.
\end{abstract}

Keywords:- Deep vein thrombosis, Parkinson disease, leg cramping, IPC machine, Pneumatic compressor, Pneumatic cylinder, Solenoid valve, Pneumatic cuff.

\section{INTRODUCTION}

This days Humans Are Threatened of musculoskeletal trauma. Musculoskeletal injuries are most common ailments which are caused by driving a long distance in a constant sitting position. So, to overcome from this pain we are going to design an Automotive Restraint which will help in relaxation in the body and a safe driving. The freedom of movement is restricted by musculoskeletal injuries and due to this situation; it may reduce your quality of life [3]. Different diseases which are caused by a constantly driving for a long distances are mention here: Deep Vein Thrombosis, Leg Cramping, Parkinson disease.

\section{$1.1 \quad$ Deep Vein Thrombosis}

It is a type of condition in which the individual experiences a blood clot inside the deep vein of lower extremities. Neglecting this situation, it may leads to death as it interferes with the circulation of the blood flow [15] in the body. Interference of the lump(mass of clotted blood) with the distribution of the blood leads to breaking off from the regular chain of circulation and enters into the bloodstream, where it causes blockage and narrows the stream making it impossible for the important organs such as brain, heart, lungs to receive an appropriate levels of oxygen in that area. So the working is like that, Heat is capable of reducing the blood clot in that part of body, it does possess the ability to reduce the risk factors associated with deep vein thrombosis. Reduction in the blood clot leads to the blood to flow freely through the veins reaching every corner of the body.

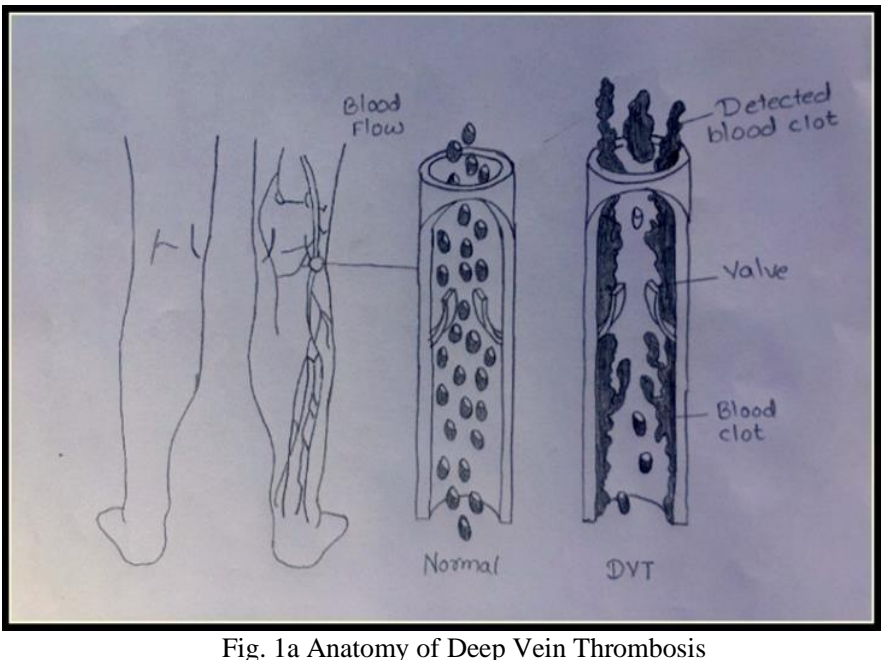

\subsection{Parkinson's disease}

It is a type of disorder that can leads to significantly impair the driving skills, cause safety concerns, and force lots of people to stop driving a car. This is because of the primary symptoms of Parkinson's disease can seriously interfere with the complex task of driving a car [4].Typically, symptoms are Rigidity, Bradykinesia, Tremor, Postural instability.

\section{$1.3 \quad$ Leg Cramping}

Lots of peoples experiences a leg cramping while driving constantly for a long distance [5].Generally, leg cramping affects the muscles in the calf (the large one is called the gastronomies) or along the sole of the foot of your leg [8]. Heat (from a heating pad) or massage of the leg and foot can help in muscles relax, although it is the best way to try stretching first which is shown in the figure below. 


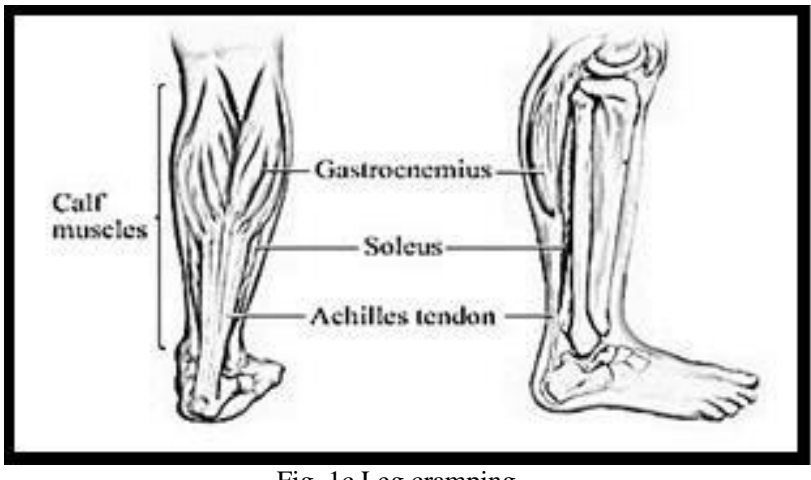

Fig. 1c Leg cramping

\section{METHODOLOGY}

Designing of Automotive Restraint is described in this section [3]. The Automotive restraint is a system which is consisted of different types of components and their relationships with each other are shown below. The illustrated components are explained as per sub-sections.

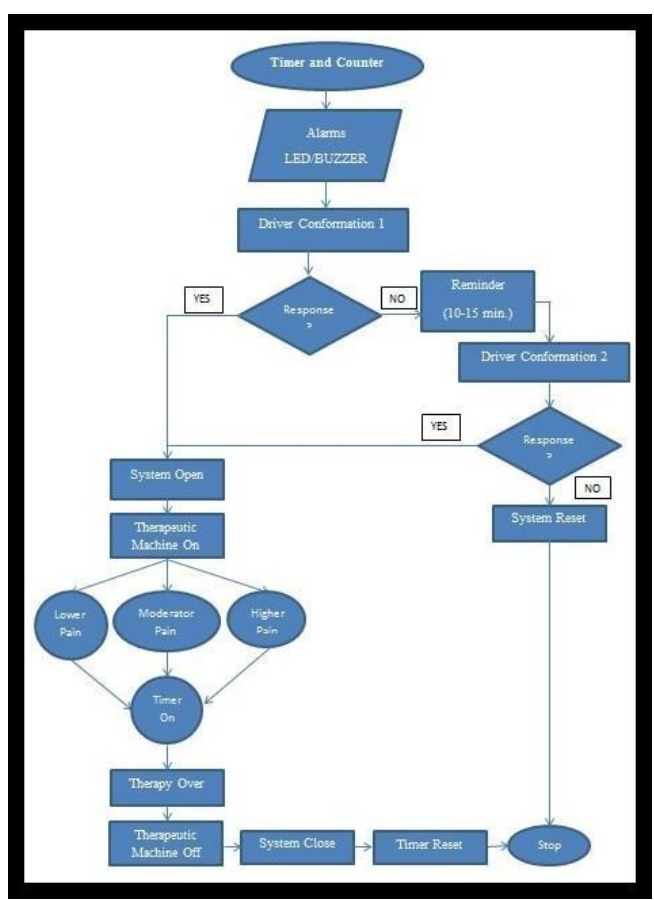

Fig.2a Flowchart of system

\section{$2.1 \quad$ Timer or counter}

As car or vehicle starts, clock will count its time based on common alarm system as per your mobile alarm system. Similarly, clock will start its pulse time which is already set in system

i.e. up to 2:30 hours of car in running mode. Counter is based upon odometer i.e. it works as, considering the kilometer from its starting point 0 - 175 kilometer when car starts riding.

\section{$2.2 \quad$ Alarm: Led/Buzzer}

Alarm will act as signal indicator which indicates the driver to take some attention on it. It will give indication in the form of LED blinking or BUZZER as sound. From this indication system starts and continues its working in forward direction. The whole system is setup in infotainment screen and led indicator is setup in odometer.

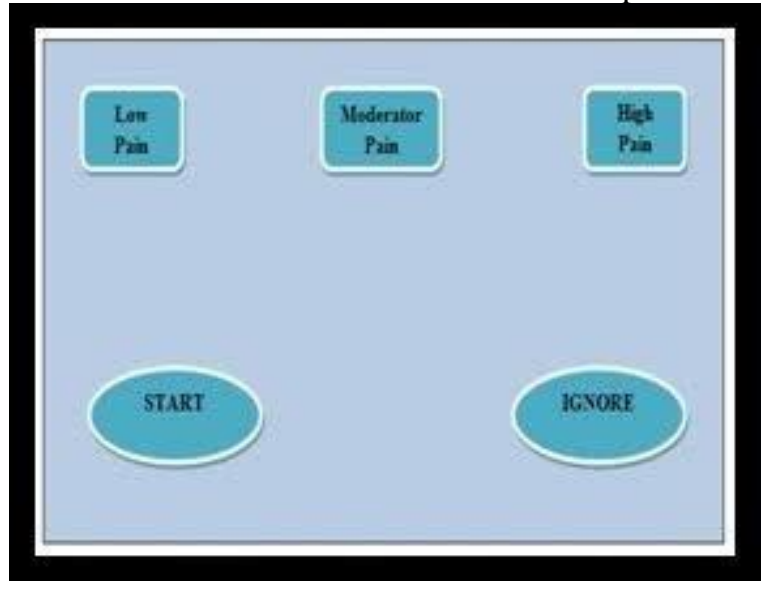

Fig.2b Infotainment screen view

\section{$2.3 \quad$ Pneumatic Cylinder}

Pneumatic Cylinder is a mechanical device which uses power of compressed gas as input to produce a force in a reciprocating linear motion. The basic fundamental through which its working is defined as, Firstly the compressed air enters into the tube at one end of the piston and imparts force on the piston [10]. Consequently, this piston displaced from its position. Here, Double-acting cylinders are used. The force of air to move the piston in both extend and retract stokes [10]. Cylinders are having two ports to allow air inside the cylinder, one for outstroke and other is instroke.

Stroke length is not limited for this proposed mechanism. However, the piston rod is more vulnerable to buckle and bend.

\section{$2.4 \quad$ Solenoid Valve}

Directional control valve is used in pneumatic system to direct or stop the flow of compressed air. The valves can have two or more ports and fulfill various circuit functions. Pneumatic solenoid valve are generally have a spool design. The ports of the valve connect to cylinder [7]. The required force to move the spool can be relatively small. Here we are going to use a Bi-Stable valve which is switched by a momentary operation. So when the operation is stopped, the valve will return to the initial situation prior to the operation. [9]. Different types of valves are also used such as 2/2-way, 5/2-way, 3/2-way. 


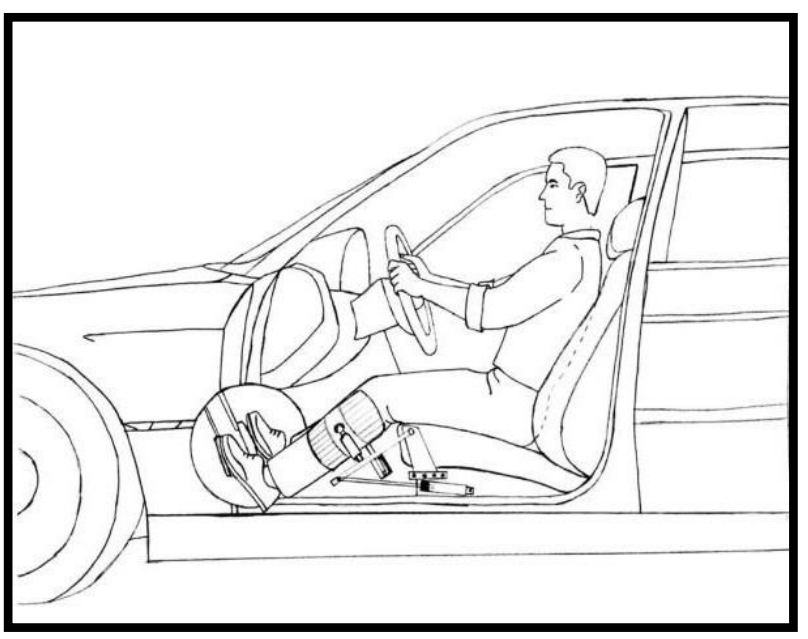

Fig. 2c Schematic diagram of system

IPC means Intermittent Pneumatic Compression therapy. It includes the use of three paired inflatable cuffs which is wrapped around the patient's lower extremities [13]. Pressure in the range of $250-275 \mathrm{~mm} / \mathrm{HG}$ is applied. It is used to prevent blood clots in the deep veins of the legs. The device uses a cuff which is wrapped around the legs and it is filled with air and squeezes your legs. Due to this it gradually increases blood flow through the veins of your legs and helps in prevention of blood clots in the leg.

The veins located in your legs contain tiny valves that help in regulating the blood back up towards the heart. Due to this disease it may damage one or more of valves. This leads to weaken or become leaky. When this situation happens, blood is getting started to pool in your leg [16].
With the help of IPC mechanism, the calf or whole leg is enclosed in the cuff. Now the cuff is filled with air and squeezes the leg, similar to a blood pressure cuff. Now the cuff deflates and relaxes. This process then repeats over and over until it is not stopped or any stopped pulse is given. The compression helps to move the blood through your veins towards your heart. It also promotes the natural release of substances in your body that help in preventing clots. Between compressions, the cuffs of the device relax, and oxygen-rich blood continues to flow in the arteries of the leg. The structural mechanism is displayed in figure number $9[16]$.

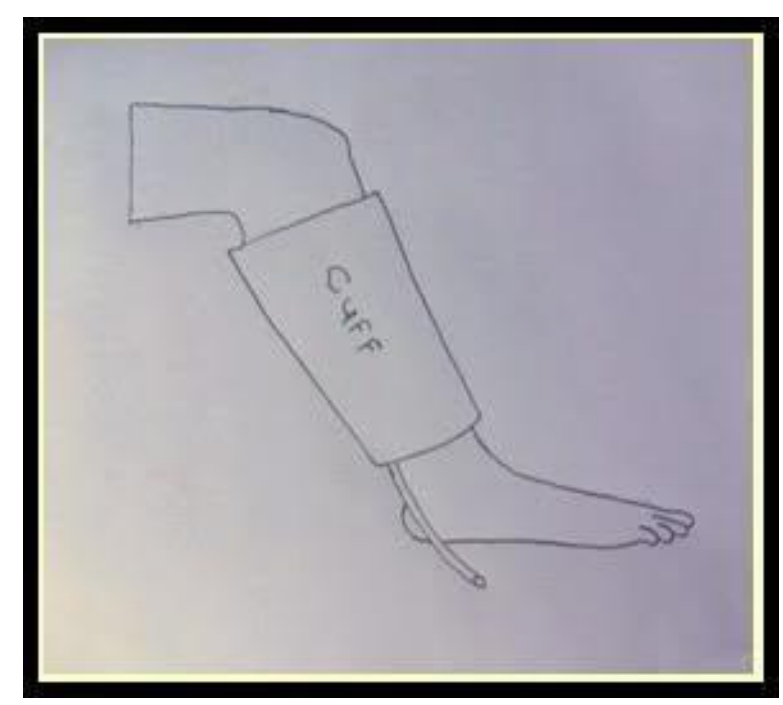

Fig. 2d Pneumatic cuff

Table 1 The main components and their specifications

\begin{tabular}{|c|c|c|c|c|}
\hline No & Material & Dimensions & $\begin{array}{l}\text { No. of } \\
\text { Pieces }\end{array}$ & Description \\
\hline 1 & $\begin{array}{l}\text { Base: } \\
\text { Stainless Steel }\end{array}$ & $\begin{array}{l}45 \mathrm{~cm} \text { length } * 0.3 \mathrm{~cm} \text { width } * \\
23 \mathrm{~cm} \text { height }\end{array}$ & 1 & Plate \\
\hline 2 & Pneumatic cylinder & $\begin{array}{l}\text { Stroke length-160, 200,250 } \\
\text { and } 320 \mathrm{~mm}\end{array}$ & 5 & Double action cylinder work synchronously \\
\hline 3 & $\begin{array}{l}\text { Pneumatic } \\
\text { cuff }\end{array}$ & $201 * 106 \mathrm{~mm}$ & 1 & Natural + synthetic rubber \\
\hline 4 & Solenoid valve & $3.5 \mathrm{~mm} \mathrm{NC} \& 2.5 \mathrm{~mm}$ NO Port & 2 & 0 to 80 psi pressure \\
\hline 5 & Compressor & $11.5 * 9 * 8$ Inch & 1 & $\begin{array}{l}12 \mathrm{~V} \text { battery operated, } \\
\text { Required } 3 \text { to } 15 \mathrm{psi} \text { pressure }\end{array}$ \\
\hline
\end{tabular}




\section{CONCLUSION}

After driving a long distance journey driver's feel pain in their lower leg and they are caught by some diseases which take their life to death also. So, to reduce such cause, we are going to design an automotive restraint which will help the drivers to feel relax after some extend of driving i.e. they will not feel bored after driving long distance. The system basically gives you a therapy in your ongoing journey to feel relax and enjoyable. This system is safe according to you and your vehicle also i.e. it will not affect your car system but we have tried to make it simple in a better way. We will include the system in your infotainment screen and odometer which help you in feeling relax and get you out of danger. This system is fully bio-compatible and eco-friendly. I have explained whole above but it needs to get in new era of world as early as possible to get rid of such disease. As per survey, I found some feel pain while driving. So to overcome from this pain I got idea to reduce this pain via building such system and I tried it.

\section{REFERENCES}

[1] Bergqvist D. Postoperative Thrombolism. Berlin, Germany: Springer-Verlag; 1983:11- 30.

[2] Haeger K. problems of acute deep venous thrombosis, I: the interpretation of signs and symptoms. Angiology. 1969;20;219223.

[3] Golgouneh, Alireza, Arshyabamshad, Bahram Tarvirdizadeh, and FarzamTajdari. "Design of a new light and portable mechanism for knee CPM machine with a user friendly interface", 2016 Artificial Intelligence and Robotics.

[4] http://www.webmd.com/

[5] https://www.centerforvein.com/the-danger-of-dvts-deep-veinthrombosis/.

[6] Parkinson J. An essay on the shaking palsy. London: Sherwood, Nelly and Jones, 1817.

[7] Beachley, N. H. and Fronczak, F. J., "Design of a free-piston Engine-pump,” SAE Technical PaperSeries, 921740, pp. 1-8, 1992.

[8] blog.seniorennet.be

[9] Wigan and Leigh College, Greater Manchester.

[10] http://www.msunites.com/wp-content/uploads/foot-drop300x128.png.

[11] Isik University.

[12] E.J. Barth, J. Zhang and M. Goldfarb, "Sliding mode approach to pwm-controlled pneumatic systems," in proc. 2002 American Control conf., 2002, pp. 2362-2367.

[13] www.vascuflo.com

[14] https://www.google.com/imgres?imgurl=https $\% 3 \mathrm{~A} \% 2 \mathrm{~F} \% 2 \mathrm{Fsm}$ http-ssl-51929.

[15] www.urmc.rochester.edu

[16] http://www.epainassist.com/ 